\title{
Study of Factors for Internal Control Effectiveness of Listed Companies
}

\author{
Jinyu $\operatorname{Tian}^{1, \text { a }}$, Sijia He $\mathrm{He}^{1, \mathrm{~b}}$ \\ ${ }^{1}$ School of Economics and Management; North China Electric Power University, Baoding 071003 , \\ a434668545@qq.com, b604526880@qq.com,
}

Keywords: The internal control; Listed companies; Effectiveness; Factor

\begin{abstract}
With the increasing and expansion scale of listed companies, effectiveness of internal control for listed companies has been gradually taken seriously. Effectiveness exaltation of internal control for listed companies to maximize enterprise value and rights protection of investors and stakeholders to strengthen government supervision over listed companies are of great significance. In this paper, based on previous study in effectiveness of internal control, firstly, effectiveness of internal control for listed companies is defined. Then factors affected effectiveness of internal control are studied to provide reference for future research, which will further promote sound and healthy development for internal control mechanisms of Listed company.
\end{abstract}

\section{The Internal Control Effectiveness of Listed Companies}

\subsection{The connotation of internal control effectiveness of listed companies}

The effectiveness of internal control based on internal controls to ensure that the degree or level to achieve the objectives of the relevant offer. If the level of assurance in effective internal control interval, the internal controls are effective; if not ensure the level of internal control within the range, the internal controls are ineffective guarantee ${ }^{[1]}$.

Effectiveness of internal control has two meanings: one refers to the company's internal control policies and measures are not inconsistent with national laws and regulations of the place; the second refers to enterprises to improve rational design of internal control framework can be very in enterprise production and business activities good to implement and can improve production efficiency, while providing true and reliable financial data to internal and external audit ${ }^{[2]}$. Effectiveness of internal controls can help companies achieve effective internal control objectives; internal control is an important guarantee to achieve the objective. From this perspective, process control, effectiveness of internal controls can be divided into the effectiveness of internal control design and operation.

\subsection{The content of internal control effectiveness of listed companies}

Internal control assessment carried out two aspects should control the design and effectiveness of internal control operation from the inside. According to China's 2008 release of "basic norms of internal control", the effectiveness of internal control design can be evaluated from the perspective of the five elements of internal control, namely: internal environment, risk assessment, control activities, information and communication, and internal oversight ${ }^{[3]}$. The effectiveness of internal control and operation of internal control goals places or not to measure, these five goals are: compliance objectives, asset security objectives, reliability of financial reporting objectives, business objectives, and strategic goals.

\section{Factor Analysis for Internal Control Effectiveness}

Departure according to the angle of internal controls five goals, factors influence the effectiveness of internal control of listed companies can be divided into internal and external factors. Internal factors are corporate governance structure, asset size enterprises, corporate culture, as well as the company's operating conditions and other external factors, as long as the environmental aspect of internal control impact, including the supervision of the relevant laws and regulations, government and external oversight audit bodies of the enterprise and auditing. 


\subsection{Internal governance structure of listed companies}

Corporate governance and internal control as the level of modern enterprise development, two flags together relying on organizations that support role, content coincidence makes will inevitably affect each other between the two.

(1) Ownership structure affects the validity of the internal control. The ownership structure is reasonable corporate governance mechanism to ensure the effective functioning play an important role in the corporate governance structure. Centralized and decentralized ownership structure is divided into two types. In the centralized ownership structure, the minority shareholders have a majority of the equity, the existence of "dominance" phenomenon. There is no balance between the interests of the shareholders, the largest shareholder abuse of control in the hands of, a serious impediment to the establishment of internal control mechanisms and listed real good ${ }^{[4]}$.

(2)The listed company internal control mechanisms affect the validity of the interior. First, the board characteristics affect the validity of the internal control. Board of directors and is the main core of corporate governance, an important position in corporate governance, the Board of Directors of the characteristics of the significant impact on the efficiency of the board of directors, and therefore more far-reaching impact on internal control ${ }^{[5]}$. Again, incentive pay on the effectiveness of internal controls. Reform and improve the pay system managers can increase the enthusiasm, stimulate the enthusiasm of the management company, making the possibility of a private consultation to reduce fraud, effectively promote the construction of internal control.

Second, the Board of Supervisors characteristics affect the validity of the internal control. In China, internal supervision systems adopt independent directors and board of supervisors of dual supervision, the Supervisory Board is under the shareholders' meeting, parallel to the board of directors, and supervision of the Board. Supervisors Board of Supervisors meeting frequency that reflects the intensity of the exercise of supervisory authority, the more frequent the meeting to reflect the degree of improvement of corporate governance, thereby contributing to the effective operation of internal control. China's actual situation, the Board of Supervisors features to improve corporate performance and no significant effects, the supervisory role of the Board of Supervisors in internal controls which play is not significant, and therefore promoting the need to strengthen the effectiveness of internal control functions of the Board of Supervisors ${ }^{[6]}$.

Third, managers of internal control features affect the validity of. First, incentives affect the validity of the internal control. In the principal-agent theory, the principal motivation is by designing a series of incentives, to convey such a message to the agent, the agent at the time of such decisions, weighing the pros and cons parties, able to make the client's interests are protected decisions. The Board must maintain its independence in order to better monitor the manager's job, so that the direction of general manager of the interests of shareholders to maximize the efforts, so that the two functional separation is more conducive to the effective operation of internal controls.

\subsection{Influence for internal control effectiveness brought by scale of enterprise assets}

Scale enterprises, mainly through the impact and the effectiveness of internal financial systems affect the quality of information disclosure of internal control. Theoretical studies indicate that the relevant scholars: firm size, the lower the quality of its financial data, that the authenticity of its financial statements for the worse ${ }^{[7]}$. It can be seen, and improving the effectiveness of internal control is one of the effective methods to improve the sound corporate financial system, strengthening the professional skills and sense of financial responsibility of employees; secondly, to provide a favorable environment for the development of SMEs. Finally, SMEs bigger and stronger to provide adequate financial support and continuously improve the financial market vigorously popularize coverage of inclusive finance, efforts to solve the financing difficulties of SMEs problems.

\subsection{Influence for internal control effectiveness brought by corporate culture}

Corporate culture is the company's internal control one of the important factors that influence the effectiveness of internal control is a key factor in the effectiveness of strategy implementation. Corporate culture is a kind of mental stimulation is an effective complement to the internal control system and design. The internal control can be divided into two parts: the company rules and 
regulations as well as corporate culture. Company rules and regulations of internal control can be achieved hard environment, through provisions to constrain the behavior of employees, to ensure that employees and business objectives consistent. However, company rules and regulations just piled series contract, the existence of loopholes in the system and drawback, which requires companies

Culture as a supplement to power support for the realization of corporate strategy. Corporate culture is a kind of soft power to motivate employees, to guide the behavior of employees having a long-term effect is to achieve long-term strategic objectives of the enterprise the best powerful tool.

Thus, to develop good corporate culture can improve the effectiveness of internal control of the Company. First, establish a good corporate culture to foster awareness of corporate integrity. Not only emphasizes employee dedication, honesty and trustworthiness, but also pay attention to the integrity of business-to-customer service, while providing good and harmonious working environment and plenty of space for development. Second, strengthen communication and exchange of information, in a timely manner to provide the necessary information to effectively solve problems for employees, reducing the degree of asymmetric information, and constantly enhance the degree of aggregation ${ }^{[8]}$.

\subsection{Influence for internal control effectiveness brought by laws and regulations}

Internal control requires a good legal environment in order to achieve the effectiveness of their control, but because of our legal system in this area is not yet perfect, affect the realization of the effectiveness of internal controls. Because of the internal control legislation is still its infancy, has yet to establish a sound legal system, from the existence of relevant laws and regulations, the prevalence of low legislative level, independent of other characteristics between content messy, laws and regulations, in our theoretical research and internal control are still in infancy, less relevant theoretical results, it is difficult for the internal control to establish and improve laws and regulations to provide effective guidance.

At present, China's laws and regulations on internal control is limited to oversee the company's accounting, legal content over a single, only to focus on the company's internal accounting controls, and therefore not a single comprehensive content, it is difficult to provide a comprehensive legal support in all positions for internal control, resulting in the effectiveness of internal control is difficult to achieve ${ }^{[9]}$. At the same time the law on corporate management and shareholder constraints still a blank, resulting in some large shareholders of privately occupied capital of the company as well as the phenomenon of the abuse of rights harm the interests of senior management shareholders of the company occur. Because of asymmetric information and other factors, the company's management there is unfettered right phenomenon, the absence of institutional constraints relevant laws and regulations, corporate governance issues emerging agents will be more prominent, making the lack of effectiveness of internal control.

\subsection{Influence for internal control effectiveness brought by external oversight audit such as government and accounting firm}

Government plays the role of the accounting firm audit and external supervision and management in the company's internal control. The first is to improve the effectiveness of internal control in the government's role. Listed companies in China are widespread a paradox: the government plays a dual role. Major shareholders of listed companies of the majority of government departments, so the microscopic point of view, the government is a listed company's managers, at the same time, a macro point of view, the role of government is responsible for the supervision of managers, this dual roles lead to the weakening of its supervisory role. Accounting firm's external audit plays a role in the quality of audit work directly affects the accounting firm auditing its effect on the company. Based on this background, our government should be in the publicity and education, internal business training, accreditation, and promote all aspects of enterprise information technology and other aspects, and strive to create a good internal control environment, improve the overall quality of internal staff for internal control to provide qualified Staffing ${ }^{[10]}$. It is important to emphasize that the enterprise information construction, management and supervision of internal control will be based on the construction of internal information on the 
realization of the internal control dynamics and timeliness, and strive to create a good environment for internal control oversight and space, so that the internal controls integrated into the corporate culture.

\section{Conclusion}

Internal control of listed companies by the combined effect of other factors and corporate governance, external governance mechanism. Internal validity listed company as the essence of internal control, the evaluation of internal control objectives plays an important role. In view of the internal control of listed companies in the problems, we need to strengthen further study of the effectiveness of internal control, improve the internal control system, and promote the healthy development of China's capital market benign.

\section{References}

[1]. Krishnan J, Audit Committee Quality and Internal Control: An Empirical Analysis[J]. The Accounting Review, 2012 (80)

[2]. Doyle J, Ge W, McVay S. Determinants of Weaknesses in Internal Control over Financial Reporting [J]. Journal of Accounting and Economics, 2013a (44)

[3]. Molz, R. Managerial Domination of Boards of Directors and Financial Performance[J]. Journal of Business Research

[4]. Abbott L J, Parker S9 PetereGF, et al. Corporate Governance, Audit Quality and the Sarbanes-Oxley Act Evidence from Internal Audit Outsourcing [J]. The Accounting Review, $2013(82)$

[5]. UdiHoistash, Rani Hoistash, Jean C. Bedard. Corporate Governance and Internal Control over Financial Reporting: A Comparison of Regulatory Regimes[J]. The Accounting Review. 2012, (3): 83-86.

[6]. Shleifer Andrei, Vishry Robert W. A Survey of Corporate Governance [J], The Journal of Finance. 2011, (2): 737-783.

[7]. Zhang I X. Economic Consequences of the Sarbanes-Oxley Act and the Flow of International Listings[J]. Journal of accounting Research, 2012, (46).

[8]. Ben Wee Goh. Internal Control Failures and Corporate Governance Structures[M]. 2012,51-57.

[9]. Jayanthi Krishanan. Auditor Committee Quality and Internal Control: An Empirical Analysis[J]. The Accounting Review. 2014, (4).

[10]. LerongHe. An Integrated System of Corporate Governance: Regulation, Internal Control and Management Attribute[J]. 2011, 40-4 